\title{
Adaptive Market Hypothesis: Evidence from three centuries of UK data
}

\author{
Ali Almail ${ }^{1} \cdot$ Fahad Almudhaf ${ }^{2 *}$ \\ ${ }^{I}$ NBK capital, Safat, Kuwait \\ ${ }^{2}$ Department of Finance and Financial Institutions, Kuwait University, Safat, Kuwait
}

Received: 30 January 2017

Revised: 14 May 2017

Accepted: 18 May 2017

\begin{abstract}
We examine the evolving efficiency of UK stock market and currency (British Pound) during the last three centuries. Using both Automatic Variance Ratio (AVR) and Automatic Portmanteau (AQ) tests, we find evidence of time-varying degree of efficiency which supports the Adaptive Markets Hypothesis (AMH).

Keywords: Adaptive Market Hypothesis (AMH); Efficient Market Hypothesis (EMH); UK stock; British Pound

JEL Classification Codes: G10, G12, G14
\end{abstract}

\section{Introduction}

Efficient Market Hypothesis (EMH) is one of the most influential theories that emerged in the field of finance. EMH in its simplest form is the idea set out by Fama $(1970,1991)$ that market prices of securities fully reflect all available information. Market efficiency is important as a feature that attracts and improves several market factors such as pricing and availability of capital, encourages foreign investment and enhances domestic savings (Al-Khazali et al. 2015). Knowledge of the behavior of markets is pivotal to academics, regulators and traders. Academics seek to support or find evidence against the concept of efficient markets, regulators aim to increase market efficiency and traders aim to exploit inefficiencies present in the market to generate abnormal profits.

According to Lo (2004), advocates of EMH believe that market forces will bring prices back to normal and rational levels, which in turn implies that the impact of behavioral biases and the irrationality of investors are generally inconsequential and immaterial. Even though the concept of EMH, where market prices rationally incorporate information, is over 45 years old, various alternative ideas emerged as a result of the introduction of behavioral economics discipline

\footnotetext{
* Corresponding author. E-mail: fmudhaf@cba.edu.kw.
}

Citation: Almail, A. and Almudhaf, F. (2017) Adaptive Market Hypothesis: Evidence from three centuries of UK data, Economics and Business Letters, 6(2), 48-53. 
arguing that markets and its participants are not rational but rather driven by other factors such as greed, fear and other behavioral biases. Lo (2004) introduced a new framework that complements the EMH with behavioral aspects by applying an evolutionary approach to economic interactions. Lo named this reconciliation the Adaptive Markets Hypothesis (AMH). It implies that market efficiency's degree fluctuates over time in different markets.

We extend and complement the work done by Charles et al. (2012) and Urquhart and Hudson (2013) by examining the efficiency of the UK stock market and British Pound over the last three centuries. By applying both the Automatic Variance Ratio (AVR) and the Automatic Portmanteau test (AQ), we find evidence of time-varying efficiency which is consistent with the AMH.

\section{Literature review}

Fama (1970) defined an efficient market as "a market with great number of rational, profitmaximizers actively competing, with each trying to predict future market values of individual securities, and where current important information is almost freely available to all participants". Critics resorted to behavioral finance to substantiate their disbelief of EMH since investors are not rational as Fama theorized, thus violating one of the pillars of the EMH. The critics of EMH often cite behavioral biases such as overreaction, over-confidence, loss aversion and others as a violation of Homo economicus, the economic concept that describes humans as constantly rational and narrowly self-interested that pursue their objectives optimally, thus disproving efficient markets. Although, the proponents of EMH argue that behavioral biases have a limited degree and persistence. As detailed by Ţiţan (2015), Fama has split EMH into three different states of efficiency: weak, semi-strong and strong form efficiency. Weak form of the EMH denotes the fact that current prices include all and any existing financial information. As a result, weak form EMH corroborate the idea of random walk or martingale which insinuates that trading on historical prices produces no profit.

The AMH has several components set out by Lo (2005). Both the EMH and AMH start with a common framework that individuals seek their self-interest first, but diverge thereafter. The AMH framework states that individuals often make mistakes, then they learn from their mistakes and adapt in response, adaptation is driven by competition, the market environment is an outcome of natural selection of survival of the wealthy and finally that all the previous components make up the dynamics of the markets. There are several implications of the AMH as pointed out by Lo (2005). One of the important testable implications is the notion that the degree of market efficiency fluctuates over time in different markets.

Multiple studies were conducted regarding the efficiency of stock markets and currencies. Charles et al. (2012) examined the return predictability of major foreign exchange rates using daily and weekly data from 1975 to 2009 by testing the Martingale Difference Hypothesis $(\mathrm{MDH})$ and three alternatives including the wild bootstrap automatic variance-test ratio test. They concluded that the returns of the exchange rate were found to be unpredictable in most of the tested periods, yet there were cycles in which return predictability was statistically significant. These periods where returns were predictable were associated with events such as central bank interventions and financial crises. This finding is consistent with the implications of AMH that predictability occasionally occurs depending on fluctuating market conditions.

Grossman and Stiglitz (1980) stipulate a theoretical argument that states if markets are perfectly efficient then trades would not be incentivized to acquire costly information. Given how impossible it is for markets to be perfectly efficient, Campbell et al. (1997) proposed an idea of relative efficiency, which has given way to new research testing the degree of efficiency. Kim et al. (2011) tested the degree of return predictability of the Dow Jones Industrial Average 
(DJIA) index using the AVR and AQ tests, and found strong evidence in favor of the implication that market efficiency is time-varying and is dependent on shifting market conditions. They discovered that during bubbles return predictability is lower than normal market conditions, while on the other hand during political and economic crises return predictability is higher than normal times. Also, during market crashes (such as the 2008 financial crisis) no predictability is present possibly to the associated uncertainty during such times. Contrary to other literature, they conclude that post 1980s the US market became more efficient given the stable fundamentals of the US economy and the improved regulatory environment in the market.

Urquhart and Hudson (2013) investigated the AMH in three stock markets (US, UK and Japan) using linear tests, such as VR test, and non-linear tests. They found out from the linear tests that the US and Japan resulted in periods of return dependencies and independencies which are consistent with the AMH theory. The UK results from linear tests demonstrated mixed types of markets, two tests exhibited return dependencies and independencies consistent with the $\mathrm{AMH}$, but one test showed that the UK is switching to efficiency. From the non-linear tests, the DJIA, FT30 and TOPIX all exhibited significant dependence indicating that markets are inefficient.

Urquhart and McGroarty (2016) examined the predictability of returns in four markets (S\&P 500, FTSE100, NIKKEI225 and EURO STOXX 50) using variations of the VR test, in addition to the BDS test. They found evidence that return predictability varies over time across different markets, which is consistent with the fourth implication specified by Lo $(2004,2005)$. They also found that certain conditions in the market are more auspicious in producing periods of significant predictability. For example, the FTSE100 shows there is considerably lower predictability during bull markets, while during normal market conditions there is a high level of predictability. While on the other hand, EURO STOXX 50 results indicated that during bull periods there is considerably higher predictability, while during down periods, periods where the average return is negative, there is considerably lower predictability. The reader can refer to Dhankar and Shankar (2016) for a detailed literature review.

\section{Data and methodology.}

The sample used in this study for UK stock covers the period April 1709 to April 2016 while the sample for British Pound covers the period January 1779 to April 2016. The monthly data is obtained from the Federal Reserve Bank of St. Louis FRED economic data ${ }^{1}$. We use AVR (Choi, 1999; Kim, 2009) and AQ (Escanciano and Lobato, 2009). The holding period value of AVR is chosen by a data driven dependent choice procedure.

$$
V R(k)=1+2 \sum_{j=1}^{n-1} m\left(\frac{j}{k}\right) \widehat{\rho}_{J}
$$

where $\widehat{\rho}_{J}=\left(\frac{n-j}{j}\right) \frac{\gamma_{j}}{\gamma_{0}}$ and $m(x)=\frac{25}{12 \pi^{2} x^{2}}\left(\frac{\sin \left(\frac{6 \pi x}{5}\right)}{\left(\frac{6 \pi x}{5}\right)}-\cos \left(\frac{6 \pi x}{5}\right)\right)$

The AQ test implements an automatic lag selection procedure.

$$
A Q_{p}=n \sum_{j=1}^{p} \widetilde{\rho_{J}^{2}}
$$

\footnotetext{
${ }^{1}$ https://fred.stlouisfed.org/categories/33849.
} 
where $\rho_{j}^{2}=\frac{\widehat{\gamma}_{j}^{2}}{\hat{\tau}_{j}}$ and $\hat{\tau}_{j}=\frac{1}{n-j} \sum_{t=j+1}^{n}\left(Y_{t}-\bar{Y}\right)^{2}\left(Y_{t-j}-\bar{Y}\right)^{2}$

\section{Results}

The tests show that the UK stock market went through alternating sub-periods of dependency and independency. This supports the AMH which implies markets go through oscillatory periods of independence and dependence return predictability. Figure 1 draws the AQ test statistic for the stock market where we can clearly see the evolving nature of efficiency. Any period where the AQ is greater than the critical value, indicates inefficiency and predictability. For example, inefficiencies were noticed during 1760-1775, 1785-1810, 1865-1870 and in recent times during 2013-2016 period. We notice the UK stock market was efficient during most periods starting from 1900 until 2000. The European sovereign debt crises that began at the end of 2009 and the Britain's vote to leave the European Union (Brexit) could be possible reasons behind the spike in the AQ of the stock market in the 2013-2016 period. The same can be found true for the British Pound as shown in Figure 2. The currency fluctuated and shifted between independent and dependent return predictability during the sub-periods of the last three centuries. The evidence found supports the notion that the efficiency of stock market and currency is fluctuating over time which are consistent with Urquhart and Hudson (2013) who studied the UK stock market for the period 1935-2009. However, the tests included a longer data span of monthly returns from 1709 to 2016.

Figure 1. Automatic Portmanteau (AQ) test results for UK stock market

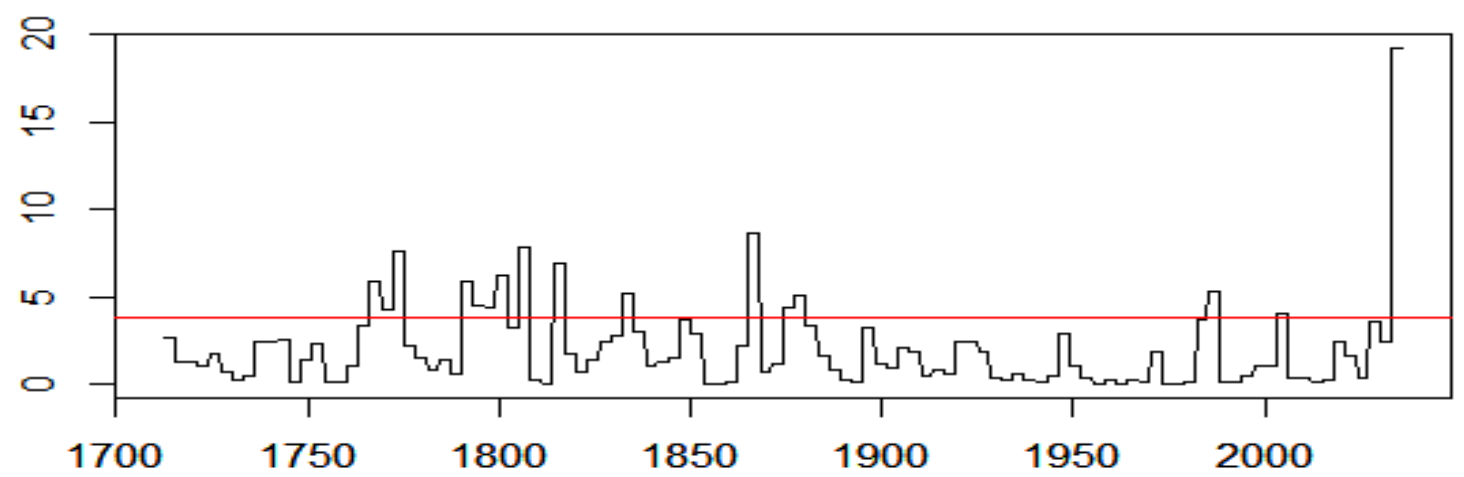

Time

Note: sample from April 1709 to April 2016. Red horizontal line is the critical value.

Figure 2. Automatic Portmanteau (AQ) test results for British Pound

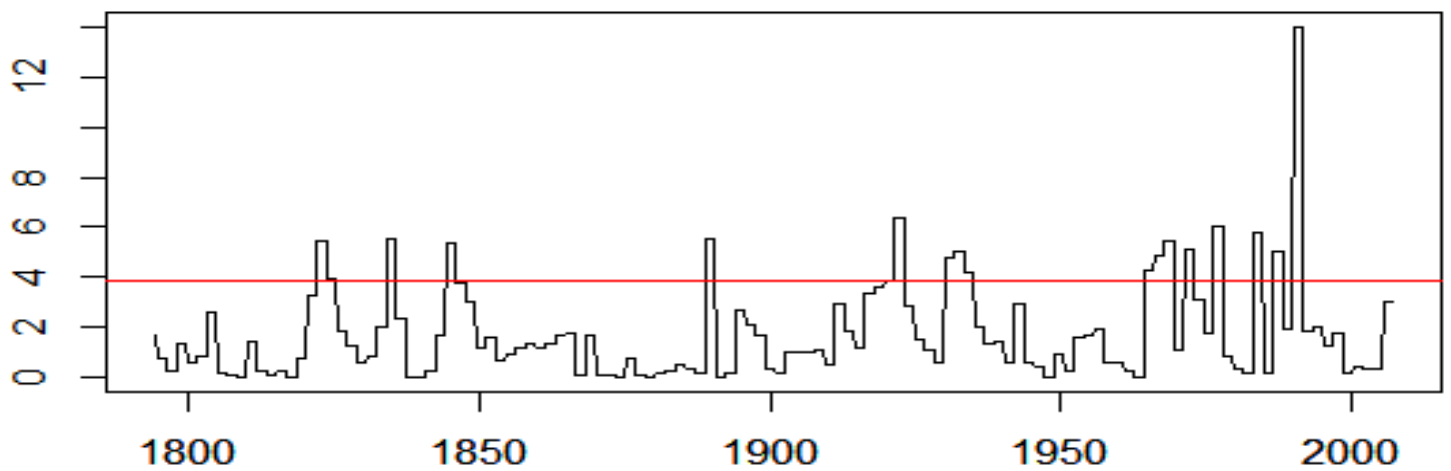

Note: sample from January 1791 to April 2016. Red horizontal line is the critical value. 
Figure 3 shows the AVR test statistic results for the stock market which reconfirms prior findings using the AQ test. Any period when the AVR statistic goes above or beyond the confidence level of the critical values (red lines), we conclude that there is slight market inefficiency. This happened during several sub-periods during our sample. For instance, this occurred during the following years of $1762,1815,1820,1845,1852,1895-1898,1970-1985$, and 20052008. There is evidence of cyclical behavior in efficiency which is consistent with AMH. When utilizing the AVR, similar results are found regarding the time-varying efficiency of the currency (British Pound). Figure 4 indicates that efficiency is changing over time which is consistent with findings from Charles et al. $(2012)^{2}$.

Figure 3. Automatic Variance Ratio (AVR) test results for UK stock market

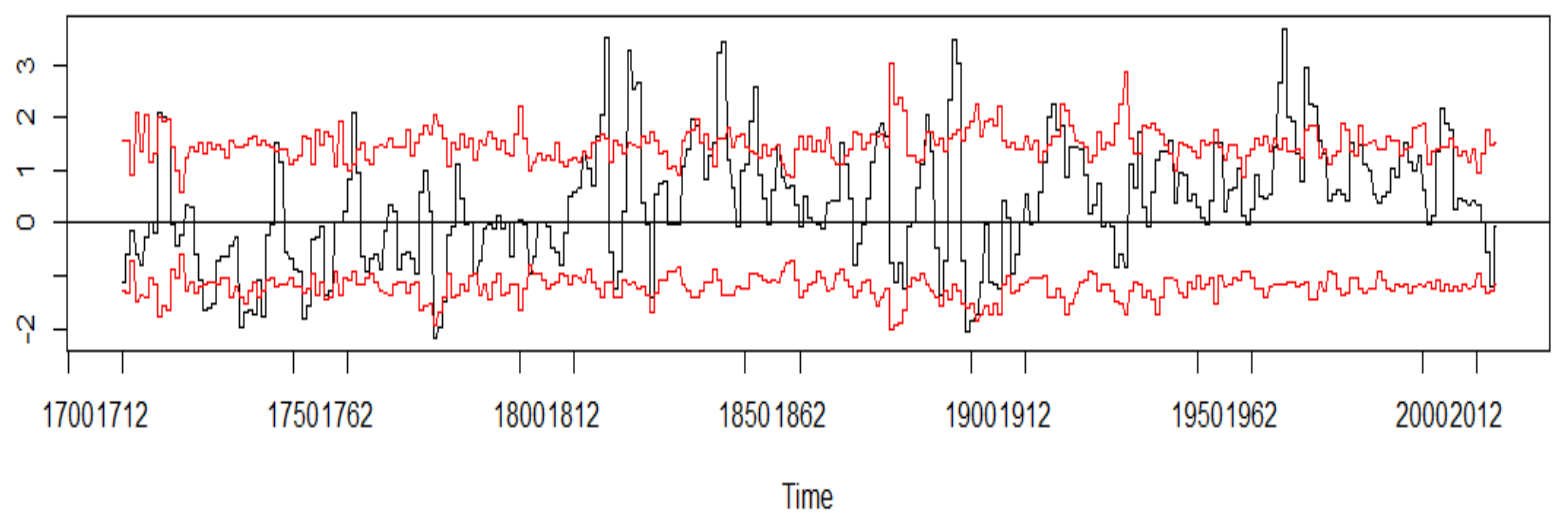

Note: sample from April 1709 to April 2016.

We use subsample window of 3 years. Red lines are the critical values.

Figure 4. Automatic Variance Ratio (AVR) test results for British Pound

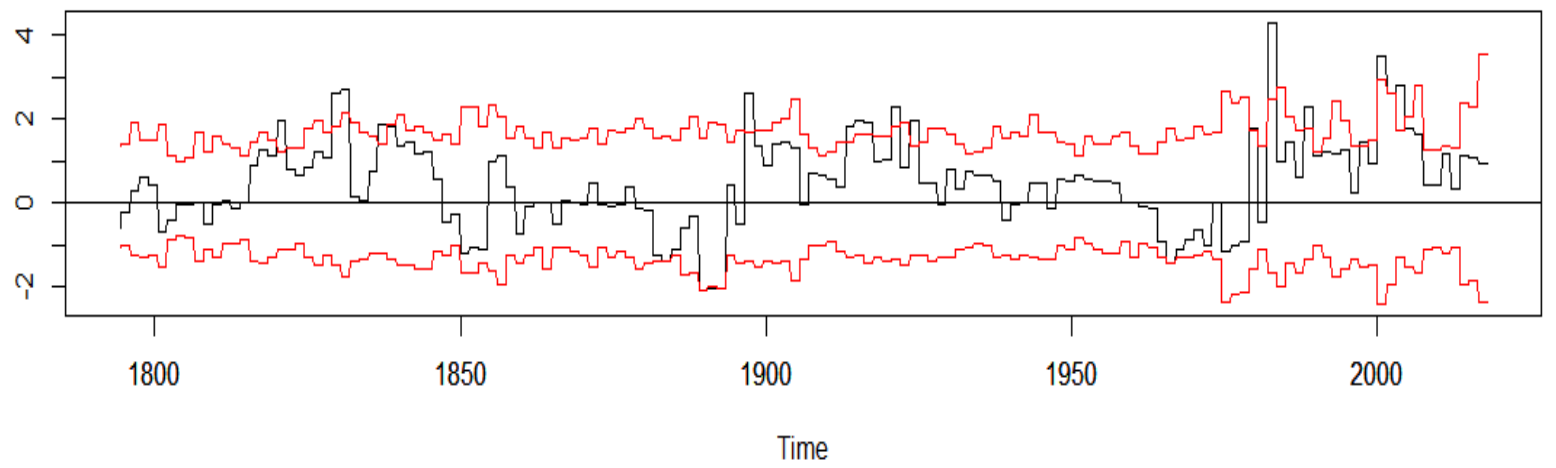

Note: sample from January 1779 to April 2016.

We use subsample window of 3 years. Red lines are the critical values.

\section{Conclusion}

We extend and complement Charles et al. (2012) and Urquhart and Hudson (2013) by examining the efficiency of UK stock market and currency during the last three centuries. Using both AVR and AQ tests, we find evidence of time-varying degree of efficiency which supports the AMH. We show that UK stock market exhibit some inefficiency during certain sub-periods

\footnotetext{
${ }^{2}$ We report our findings using a rolling window of 3 years. However, our main conclusions should not be sensitive to different choices of window length. Kim et al. (2011) show that their results, both daily and weekly, are insensitive to window length. Also, Lim et al. (2013) argue that there is no theory on the optimal window length. We thank the reviewer for this comment.
} 
when returns depend on that of past historical periods. We do not see a clear trend of improving efficiency through time. Episodes of irrationality, shocks to markets and several behavioral and fundamental factors could cause markets and currencies to go through episodes of informational inefficiency for some time periods. Thus, practitioners should continue to devise trading strategies aiming to exploit such temporary inefficiencies.

\section{References}

Al-Khazali, O.M., Guillaume L. and Alsayed, M.S. (2015) A Market Efficiency Comparison of Islamic and Non-Islamic Stock Indices, Emerging Markets Finance and Trade, 938, $1-19$.

Campbell, J.Y., Lo, A.W. and MacKinlay, A.C. (1997) The Econometrics of Financial Markets, Princeton University Press, Princeton.

Charles, A., Olivier D. and Kim, J.H. (2012) Exchange-rate return predictability and the adaptive markets hypothesis: Evidence from major foreign exchange rates. Journal of International Money and Finance, 31, 1607-1626.

Choi, I. (1999) Testing the random walk hypothesis for real exchange rates, Journal of Applied Economics, 14(3), 293-308.

Dhankar, R.S. and Shankar, D. (2016) Relevance and evolution of adaptive markets hypothesis: a review, Journal of Indian Business Research, 8(3), 166-179.

Escanciano, J.C. and Lobato, I.N. (2009) An automatic Portmanteau test for serial correlation, Journal of Econometrics, 151, 140-149.

Fama, E.F. (1970) Efficient capital markets: A review of theory and empirical work, Journal of Finance, 25(2), 383-417.

Fama, E.F. (1991) Efficient Capital Markets, Journal of Finance, 46, 383-417.

Grossman, S.J. and Stiglitz, J.E. (1980) On the Impossibility of informationally Efficient Markets, American Economic Review, 70, 393-408.

Kim, J.H. (2009) Automatic variance ratio test under conditional heteroskedasticity, Finance Research Letters, 6(3), 179-185.

Kim, J.H., Shamsuddin, A. and Lim, K.P. (2011) Stock return predictability and the adaptive markets hypothesis: Evidence from century-long US data, Journal of Empirical Finance, 18, 868-879.

Lim, K.P., Luo, W. and Kim, J.H. (2013) Are US stock index returns predictable? Evidence from automatic autocorrelation-based tests, Applied Economics, 45(8), 953-962.

Lo, A.W. (2004) The Adaptive Markets Hypothesis, Journal of Portfolio Management, 30, 1529.

Lo, A.W. (2005) Reconciling Efficient Market with Behavioral Finance: The Adaptive Markets Hyphotesis, Journal of Investment Consulting, 7, 1-25.

Ţiţan, A.G. (2015) The Efficient Market Hypothesis: Review of Specialized Literature and Empirical Research, Procedia Economics and Finance, 32, 442-449.

Urquhart, A. and Hudson, R. (2013) Efficient or adaptive markets? Evidence from major stock markets using very long run historic data, International Review of Financial Analysis, $28,130-142$.

Urquhart, A. and McGroarty, F. (2016) Are stock markets really efficient? Evidence of the adaptive market hypothesis, International Review of Financial Analysis, 47, 39-49. 